\title{
Physical inactivity and obesity: links with insulin resistance and type 2 diabetes mellitus
}

\author{
Michelle C. Venables* \\ Asker E. Jeukendrup
}

Exercise Metabolism Research Group, Human Performance Laboratory, School of Sport and Exercise Sciences, The University of Birmingham, Edgbaston, Birmingham, B15 2TT, UK

*Correspondence to:

Michelle C. Venables, School of life sciences, Oxford Brookes University, Gipsy Lane, Headington, Oxford, OX3 OBP.

E-mail:

michelle.venables@brookes.ac.uk

\section{Summary}

Data from the health survey for England 2006 [1], showed that the prevalence of type 2 diabetes mellitus (T2DM) has more than doubled in men and women since 1991. In the USA certain States have a prevalence of T2DM of greater than $10 \%$ [2]. Globally it has been reported that this increase is by no means slowing down and that the number of individuals with the disease is expected to rise from 171 million cases reported in 2000 to 366 million by the year 2030 [3]. Physical inactivity and obesity are two major risk factors for the development of T2DM. In this review we will discuss evidence of an association between physical inactivity, obesity and T2DM from prospective cohort studies and clinical trials. We will also discuss some of the potential mechanisms that are thought to link obesity and physical inactivity with the major pathophysiological precursor of T2DM, insulin resistance. Copyright (c) 2009 John Wiley \& Sons, Ltd.

Keywords insulin signaling; Fatty acid intermediates; intramuscular triacylglycerol

\section{Prospective studies and clinical trials}

Many prospective studies have been published over the last two decades reporting strong associations between daily physical activity and a reduced risk of developing T2DM (Table 1). Helmrich et al. investigated 5990 male alumni from the University of Pennsylvania and reported a negative relationship between incidence of type 2 diabetes and physical activity [4]. Indeed, for every increase in leisure time energy expenditure of $500 \mathrm{kcal}$, the age-adjusted risk for developing T2DM decreased by 6\%. This relationship held strong even when adjustments were made for obesity, hypertension and a parental history of diabetes. These findings were later replicated in a much larger cohort of women. The Nurses' Health Study [5] followed 70102 registered nurses and reported a progressive reduction in the age-adjusted relative risk of T2DM with increasing physical activity.

Following on from these earlier studies, similar findings have been reported in studies across the globe. Studies from the UK [6], Japan [7], Finland [8] and Germany [9] have reported a reduction in relative risk for the development of T2DM of between 15 and $60 \%$ with increased daily physical activity. In addition, $\mathrm{Hu}$ et al. [8] displayed eloquently the relative risk of developing T2DM with not only physical activity quintiles but also those of body mass index (BMI) and impaired glucose regulation. The authors showed that an increase in BMI drastically increased the relative risk for development of T2DM whilst physical inactivity in normal weight individuals had a

Received: 
Table 1. Prospective studies implicating physical inactivity as a risk factor in the development of type 2 diabetes

\begin{tabular}{|c|c|c|c|}
\hline Author & Participants & Comments & Country of study \\
\hline Helmrich et al. [4] & $5990 \mathrm{M}$ & $\begin{array}{l}\downarrow \text { Age-adjusted risk of } 6 \% \text { every } 500 \text { kcal of leisure } \\
\text { time physical activity }\end{array}$ & US \\
\hline Perry et al. [6] & $7735 \mathrm{M}$ & $\begin{array}{l}\downarrow \text { Relative risk of } 60 \% \text { between moderately active } \\
\text { men and inactive men }\end{array}$ & $U^{a}$ \\
\hline Hu et al. [5] & $70102 \mathrm{~W}$ & $\begin{array}{l}\downarrow \text { Relative risk of } 26 \% \text { between upper and lower } \\
\text { quintile of physical activity }\end{array}$ & US \\
\hline Nakanishi et al. [7] & $2924 \mathrm{M}$ & $\begin{array}{l}\downarrow \text { Adjusted relative risk of } 59 \% \text { between upper and } \\
\text { lower quintile of physical activity }\end{array}$ & Japan \\
\hline Hu et al. [8] & $2017 \mathrm{M}$ and $2352 \mathrm{~W}$ & $\begin{array}{l}\downarrow \text { Adjusted relative risk of } 15 \text { and } 57 \% \text { between } \\
\text { moderate and high compared to low physical } \\
\text { activity }\end{array}$ & Finland \\
\hline Meisinger et al. [9] & $4069 \mathrm{M}$ and $4034 \mathrm{~W}$ & $\begin{array}{l}\downarrow \text { Adjusted relative risk of } 13,30 \text { and } 76 \% \text { between } \\
\text { low, moderate and high compared to no physical } \\
\text { activity }\end{array}$ & Germany ${ }^{c}$ \\
\hline
\end{tabular}

M, men; W, women.

${ }^{a}$ British Regional Heart Study.

'The Nurses' Health Study.

'The MONICA/KORA Augsburg Cohort Study.

much attenuated effect. Pooling the data they concluded that those individuals with a BMI $\geq 30 \mathrm{~kg} / \mathrm{m}^{2}$, partake in low levels of physical activity, have impaired glucose regulation and are 30 times more likely to develop type 2 diabetes than normal weight, active normal glucose tolerant individuals. A similar finding was reported by Weinstein et al. [10] who followed 37878 women for an average of 6.9 years. They concluded that both BMI and physical inactivity were predictors of T2DM incidence, but that the magnitude of the association with BMI was greater than with physical inactivity.

In addition to the aforementioned prospective studies, clinical trials, in which lifestyle modifications were made, have reported that the addition of physical activity and dietary modification can reduce the incidence of T2DM. The Da Qing Impaired Glucose Tolerance (IGT) and Diabetes Study [11] investigated 577 men and women with IGT every 2 years over a 6 -year period. The men and women were randomized into one of four groups; control, diet only, exercise only and diet plus exercise. The cumulative incidences of T2DM after 6 years were $67.7 \%$ for control, $43.8 \%$ for diet only, $41.1 \%$ for exercise only and $46.0 \%$ for diet and exercise. When adjusted for difference in baseline BMI and fasting glucose the risk of developing T2DM was decreased by $31 \%$ by diet only, $46 \%$ by exercise only and $42 \%$ by diet and exercise.

Furthermore, The Diabetes Prevention Program [12] a large randomized clinical trial in adults at risk for the development of T2DM, compared lifestyle intervention with drug therapy. A total of 3234 participants were assigned to one of three groups; control, metformin and lifestyle intervention for an average of 2.8 years. The lifestyle intervention was designed such that individuals achieved and maintained weight loss of $7 \%$ and engaged in physical activity for $150 \mathrm{~min} /$ week. Participants in the lifestyle modification group lost significantly more weight and increased physical activity to a greater extent than either the metformin or control groups. Both the metformin and lifestyle modification groups had a significant reduction in the cumulative incidence of T2DM compared to the control group (58\% and 31\%, lifestyle and metformin respectively). Interestingly, the lifestyle intervention was far more effective in reducing the risk of developing T2DM than the metformin group.

In summary, it has been shown that obesity and physical inactivity are risk factors for the development of T2DM. Furthermore, $80 \%$ of type 2 diabetics are obese and sedentary. It appears that a sedentary lifestyle (physical inactivity) results in various symptoms of disease reduced insulin sensitivity in the early stages and T2DM as the disease is progressing. It is therefore important to understand how inactivity causes IGT, reduced insulin resistance and ultimately T2DM. In healthy humans, skeletal muscle accounts for between 70 and $80 \%$ of insulin-stimulated glucose uptake [13] and, skeletal muscle is the principal peripheral site of insulin resistance in T2DM $[14,15]$. The muscle is also responsible for the most variable component of daily energy expenditure: the thermic effect of exercise. This component can be reduced to very low levels with a sedentary lifestyle. The remainder of this review will therefore focus on the underlying mechanisms within skeletal muscle thought to link obesity and a sedentary lifestyle with insulin resistance and the onset of T2DM.

\section{Obesity, fatty acid uptake and oxidation}

Where adipose tissue is the principal organ for fatty acid storage, skeletal and cardiac muscle are the most important organs for fatty acid oxidation. Fatty acids are mobilized from adipose tissue and transported to the muscle for uptake and oxidation. In obesity, there appears to be a mismatch between uptake of fatty acids into skeletal muscle and oxidation, leading to excessive accumulation of triacylglycerol and fatty acid metabolites such as long chain acyl-CoAs, diacylglycerols and ceramides in the sarcoplasm. 
Increased lipid accumulation within skeletal muscle may occur through two mechanisms; either an increased uptake and/or a decreased oxidation of fatty acids. In obesity skeletal muscle is usually chronically exposed to high plasma fatty acid concentrations which could drive an increased uptake into the muscle. However, it has been shown that the uptake of fatty acids (palmitate) into giant vesicles prepared from skeletal muscle is increased in insulin resistant skeletal muscle of obese Zucker rats [16] as well as obese and type 2 diabetic patients [17]. This increased uptake was observed even when the palmitate concentration in the bathing medium was equal and is suggested to be due to an increase in proteins involved in fatty acid uptake. Both fatty acid binding protein (FABPpm) [18] and fatty acid translocase (FAT)/CD36 [17] are increased in obesity. In the case of FAT/CD36 total protein content is not increased but it is permanently translocated from intracellular depots to the plasma membrane, thus facilitating fatty acid uptake [19]. Additionally, a second likely explanation for the accumulation of lipid within skeletal muscle is a reduction in fat oxidation. Dobbins et al. [20] reported that chronic inhibition (4-week) of fatty acid uptake into the mitochondria using a pharmacological inhibitor of carnitine palmitoyltransferase- 1 resulted in intramuscular triacylglycerol (IMTG) accumulation and insulin resistance in rats. In humans a reduction in postabsorptive fat oxidation has been reported frequently in obesity and T2DM when compared with lean individuals [21-25] and this reduction remains post weight loss [26,27].

\section{IMTG accumulation and insulin resistance}

It has been suggested that the increased availability and uptake of circulating fatty acids alongside an impairment in the ability to oxidize fat lead to the accumulation of IMTG [20] and fatty acid metabolites such as long chain acyl-CoAs, diacylglycerols and ceramides in obesity. Elevated IMTG accumulation has been observed in obesity $[28,29]$ and there is a large body of evidence to suggest that the accumulation of IMTG correlates with insulin resistance and the development of T2DM [28,30-37]. In addition to these observational studies, intervention studies that are typically associated with increased insulin sensitivity such as weight loss [38] have shown reductions in IMTG content [28]. Furthermore, increasing IMTG via high fat feeding can decrease insulin sensitivity in rats [39]. However, paradoxically, when endurance trained athletes are included in these relationships the strong correlation observed disappears [30,40] because endurance trained athletes are highly insulin sensitive yet have elevated IMTG content [30]. Further dissociation between IMTG and insulin resistance becomes apparent when examining recent exercise training data. Exercise training can increase insulin sensitivity despite an elevated
IMTG content in sedentary older adults [41] and sedentary overweight obese individuals [42]. As there is an apparent dissociation between IMTG content and insulin resistance it has been suggested that IMTG accumulation is a surrogate marker for the accumulation of other lipid intermediates that can modulate insulin signaling.

\section{Fatty acid intermediates and insulin signaling}

Studies in which circulating plasma fatty acid concentrations have been acutely raised have lead to insulin resistance in human skeletal muscle [19,43-45]. In addition chronic ( $4 \mathrm{~d}$ ) lipid infusions have produced a similar response [46]. Conversely, pharmacological reduction in circulating plasma fatty acid concentrations using acipimox in individuals with chronically elevated fatty acid concentrations has been shown to improve insulin resistance overnight $[47,48]$. Furthermore, inactivation of fatty acid transport protein 1 , which is important in fatty acid uptake and subsequent conversion to fatty acyl-CoA within the skeletal muscle prevents the insulin resistance observed with high fat feeding and lipid infusions in mice [49].

Belfort et al. [43] reported that an elevation in circulating fatty acids within the physiological range was associated with a decrease in insulin-stimulated insulin receptor tyrosine phosphorylation, insulin receptor substrate (IRS)-1 tyrosine phosphorylation, IRS-1 associated phosphatidylinositol (PI) 3-kinase activity, Akt serine phosphorylation and glucose disposal rates. In addition to the decreased insulin activation of IRS-1 tyrosine phosphorylation and IRS-1 associated PI3-kinase activity lipid infusion is associated with an increase in long-chain acyl$\mathrm{CoA}$ and diacylglycerol content within the skeletal muscle $[50,51]$.

There is now an attractive hypothesis that suggests a mechanistic link between the accumulation of fatty acyl-CoAs and diacylglycerols and insulin resistance (Figure 1). Skeletal muscle diacylglycerol content is increased in human and animal models of insulin resistance [50,51] and this can activate specific isoforms of protein kinase C (PKC) which can inhibit insulin signal transduction thought to be through serine phosphorylation of IRS-1 [51]. Aguirre et al. [52] have shown that phosphorylation on a specific serine site, serine 307, of IRS-1 can block the phospho tyrosine binding domain functions of the IRS-1 protein thereby inhibiting the downstream signaling events such as PI3kinase activation.

Evidence implicating PKC comes from observations in lipid induced insulin resistance models. Griffin et al. [53], infused rats with lipid/heparin for $5 \mathrm{~h}$ and found that the membrane fraction of PKC $\theta$ was increased fourfold. This increase in membrane bound PKC $\theta$ was associated with a blunting in insulin-stimulated IRS-1 tyrosine phosphorylation and a 50\% reduction in insulinstimulated IRS-1-associated PI3-kinase activity. The same 


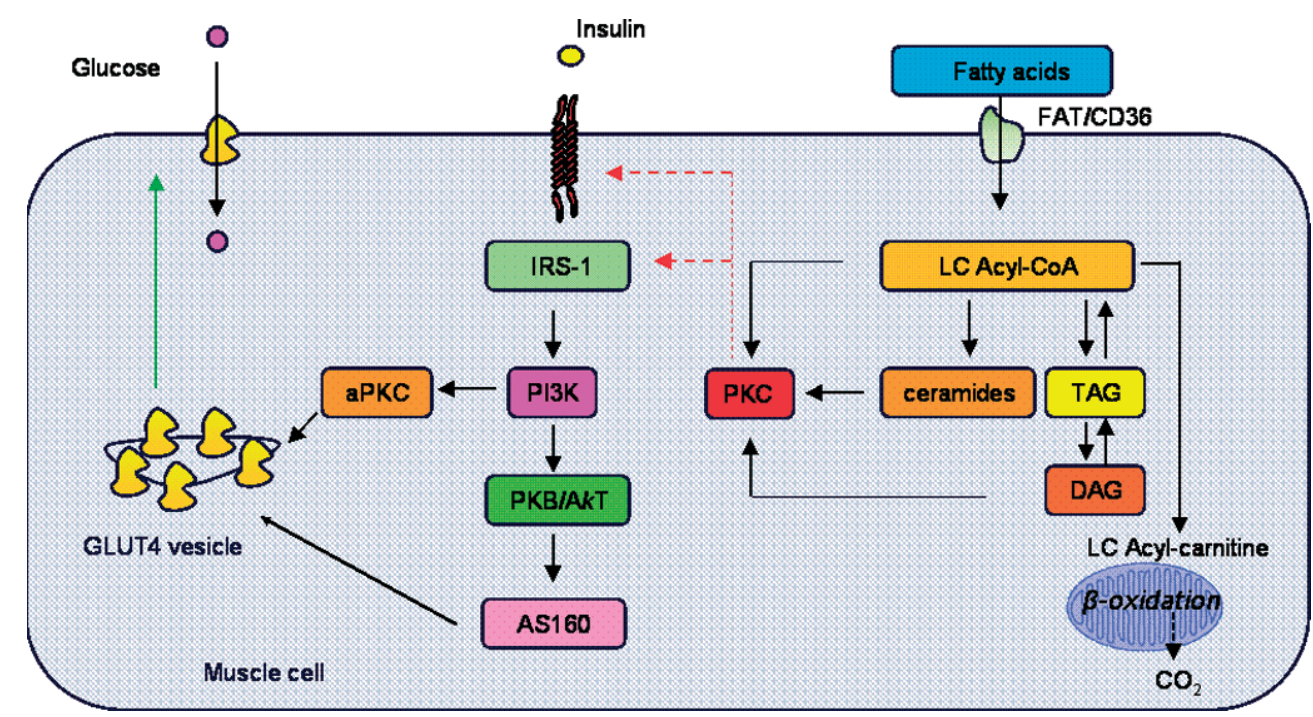

Figure 1. Lipids and insulin resistance. aPKC, atypical protein kinase C; IRS-1, insulin receptor substrate-1; PI3K, phosphatidyl-3-kinase; PKB, protein kinase B; AS160, Akt substrate of $160 \mathrm{kDa}$; nPKC, novel isoforms of PKC; LC, long chain; TAG, triacylglycerol; DAG, diacylglycerol; FAT/CD36, fatty acid translocase CD36. Dotted lines indicate inhibitory pathways, solid lines indicate activation

is evident in human models. When healthy volunteers were infused for $6 \mathrm{~h}$ with lipid/heparin a reduction in glucose disposal was associated with a four-fold increase in membrane bound PKC [50]. Moreover PKC $\theta$ knockout mice are protected against fat induced insulin resistance [54] and it has been demonstrated in cell lines [55-58] and rats $[53,59,60]$ that PKC can inhibit IRS- 1 tyrosine kinase activity and reduce insulin-stimulated glucose uptake. In human skeletal muscle strips a cause and effect relationship has been observed between PKC activation and insulin-stimulated glucose uptake. Using human skeletal muscle strips from lean and obese individuals Cortright et al. demonstrated that in insulin resistant muscle the addition of a PKC inhibitor could increase glucose uptake. Conversely in insulin sensitive muscle the addition of a PKC activator could depress insulinstimulated glucose uptake [61].

\section{$\beta$-0xidation and insulin signaling}

In contrast to the lipid accumulation theory, Perdomo et al. [62] demonstrated, in L6 myotubes, that an increase in $\beta$ oxidation induced by an overexpression of carnitine palmitoyltransferase- 1 increased insulinstimulated glucose uptake in the absence of any perturbations in IMTG, diacylglycerol, ceramide or long chain acyl-CoAs. In line with this finding, recent data from Thyfault et al. [63] has indicated that elevations in mitochondrial oxidative capacity following an acute bout of exercise can increase insulin-stimulated glucose uptake in the absence of any decrease in diacylglycerol or long chain acyl-CoAs. Indeed, it was observed that long chain acyl-CoAs increased following exercise. It has therefore been speculated that acute exercise induces a coordinated increase in $\beta$-oxidation with an up-regulation of the tricarboxylic acid (TCA) cycle, such that complete fatty acid oxidation takes place [64] and the resultant acetylcarnitines are immediately taken into the TCA cycle [63]

\section{Conclusions}

Being overweight or obese and leading a sedentary lifestyle are two significant predictors of insulin resistance and T2DM development. It would seem that the influence of overweight/obesity is far greater than that of being physically inactive when interpreting the magnitude of relative risk of T2DM development. Lifestyle interventions that include regular physical activity and dietary modification can delay and even prevent the onset of such diseases. A possible mechanism through which lifestyle interventions exert their effects is thought to include an increase in fat oxidation following a period of exercise training. This mechanism has been shown to reduce the accumulation of fatty acid species such as fatty acyl-CoAs, diacylglycerols and ceramides within the skeletal muscle, thus attenuating the inhibition on the insulin signaling pathway. Moreover, an early response to exercise training could include a coordination of the increase in $\beta$ oxidation with an up-regulation of the TCA cycle leading to a decrease in the accumulation of diabetogenic $\beta$-oxidation intermediates.

\section{Conflict of interest}

None declared.

\section{References}

1. DOH. Health Survey for England 2005 Latest Trends, edited by Department of Epidemiology and Public Health UCL (ed). HMSO: London, 2006. 
2. Mokdad AH, Ford ES, Bowman BA, et al. Prevalence of obesity, diabetes, and obesity-related health risk factors, 2001. JAMA 2003; 289: 76-79.

3. Wild S, Roglic G, Green A, Sicree R, King H. Global prevalence of diabetes: estimates for the year 2000 and projections for 2030. Diabetes Care 2004; 27: 1047-1053.

4. Helmrich SP, Ragland DR, Leung RW, Paffenbarger RS Jr. Physical activity and reduced occurrence of non-insulindependent diabetes mellitus. N Engl J Med 1991; 325: 147-152.

5. Hu FB, Sigal RJ, Rich-Edwards JW, et al. Walking compared with vigorous physical activity and risk of type 2 diabetes in women: a prospective study. JAMA 1999; 282: 1433-1439.

6. Perry IJ, Wannamethee SG, Walker MK, Thomson AG, Whincup PH, Shaper AG. Prospective study of risk factors for development of non-insulin dependent diabetes in middle aged British men. BMJ 1995; 310: 560-564.

7. Nakanishi N, Takatorige T, Suzuki K. Daily life activity and risk of developing impaired fasting glucose or type 2 diabetes in middle-aged Japanese men. Diabetologia 2004; 47: 1768-1775.

8. Hu G, Lindstrom J, Valle TT, et al. Physical activity, body mass index, and risk of type 2 diabetes in patients with normal or impaired glucose regulation. Arch Intern Med 2004; 164: 892-896.

9. Meisinger C, Lowel H, Thorand B, Doring A. Leisure time physical activity and the risk of type 2 diabetes in men and women from the general population. The MONICA/KORA Augsburg Cohort Study. Diabetologia 2005; 48: 27-34.

10. Weinstein AR, Sesso HD, Lee IM, et al. Relationship of physical activity vs body mass index with type 2 diabetes in women. JAMA 2004; 292: 1188-1194.

11. Pan XR, Li GW, Hu YH, et al. Effects of diet and exercise in preventing NIDDM in people with impaired glucose tolerance. The Da Qing IGT and Diabetes Study. Diabetes Care 1997; 20: 537-544.

12. Knowler WC, Barrett-Connor E, Fowler SE, et al. Reduction in the incidence of type 2 diabetes with lifestyle intervention or metformin. N Engl J Med 2002; 346: 393-403.

13. DeFronzo RA, Jacot E, Jequier E, Maeder E, Wahren J, Felber JP. The effect of insulin on the disposal of intravenous glucose. Results from indirect calorimetry and hepatic and femoral venous catheterization. Diabetes 1981; 30: 1000-1007.

14. Baron AD, Laakso M, Brechtel G, Edelman SV. Reduced capacity and affinity of skeletal muscle for insulin-mediated glucose uptake in noninsulin-dependent diabetic subjects. Effects of insulin therapy. J Clin Invest 1991; 87: 1186-1194.

15. DeFronzo RA, Gunnarsson R, Bjorkman O, Olsson M, Wahren J. Effects of insulin on peripheral and splanchnic glucose metabolism in noninsulin-dependent (type II) diabetes mellitus. $J$ Clin Invest 1985; 76: 149-155.

16. Luiken JJ, Arumugam Y, Dyck DJ, et al. Increased rates of fatty acid uptake and plasmalemmal fatty acid transporters in obese Zucker rats. $J$ Biol Chem 2001; 276: 40567-40573.

17. Bonen A, Parolin ML, Steinberg GR, et al. Triacylglycerol accumulation in human obesity and type 2 diabetes is associated with increased rates of skeletal muscle fatty acid transport and increased sarcolemmal FAT/CD36. FASEB $J$ 2004; 18: $1144-1146$

18. Simoneau JA, Veerkamp JH, Turcotte LP, Kelley DE. Markers of capacity to utilize fatty acids in human skeletal muscle: relation to insulin resistance and obesity and effects of weight loss. FASEB J 1999; 13: 2051-2060.

19. Boden G, Lebed B, Schatz M, Homko C, Lemieux S. Effects of acute changes of plasma free fatty acids on intramyocellular fat content and insulin resistance in healthy subjects. Diabetes 2001; 50: 1612-1617.

20. Dobbins RL, Szczepaniak LS, Bentley B, Esser V, Myhill J, McGarry JD. Prolonged inhibition of muscle carnitine palmitoyltransferase-1 promotes intramyocellular lipid accumulation and insulin resistance in rats. Diabetes 2001; 50: $123-130$

21. Colberg SR, Simoneau JA, Thaete FL, Kelley DE. Skeletal muscle utilization of free fatty acids in women with visceral obesity. J Clin Invest 1995; 95: 1846-1853.

22. Hulver MW, Berggren JR, Cortright RN, et al. Skeletal muscle lipid metabolism with obesity. Am J Physiol Endocrinol Metab 2003; 284: E741-E747.

23. Kelley DE, Goodpaster B, Wing RR, Simoneau JA. Skeletal muscle fatty acid metabolism in association with insulin resistance, obesity, and weight loss. Am J Physiol 1999; 277: E1130-E1141.

24. Kelley DE, Simoneau JA. Impaired free fatty acid utilization by skeletal muscle in non-insulin-dependent diabetes mellitus. $J$ Clin Invest 1994; 94: 2349-2356.

25. Kim JY, Hickner RC, Cortright RL, Dohm GL, Houmard JA. Lipid oxidation is reduced in obese human skeletal muscle. Am J Physiol Endocrinol Metab 2000; 279: E1039-E1044.

26. Guesbeck NR, Hickey MS, MacDonald KG, et al. Substrate utilization during exercise in formerly morbidly obese women. J Appl Physiol 2001; 90: 1007-1012.

27. Thyfault JP, Kraus RM, Hickner RC, Howell AW, Wolfe RR, Dohm GL. Impaired plasma fatty acid oxidation in extremely obese women. Am J Physiol Endocrinol Metab 2004; 287: E1076-E1081

28. Goodpaster BH, Theriault R, Watkins SC, Kelley DE. Intramuscular lipid content is increased in obesity and decreased by weight loss. Metabolism 2000; 49: 467-472.

29. Malenfant $P$, Joanisse DR, Theriault R, Goodpaster BH, Kelley DE, Simoneau JA. Fat content in individual muscle fibers of lean and obese subjects. Int J Obes Relat Metab Disord 2001; 25: 1316-1321.

30. Goodpaster BH, He J, Watkins S, Kelley DE. Skeletal muscle lipid content and insulin resistance: evidence for a paradox in endurance-trained athletes. $J$ Clin Endocrinol Metab 2001; 86: $5755-5761$.

31. Goodpaster BH, Thaete FL, Simoneau JA, Kelley DE. Subcutaneous abdominal fat and thigh muscle composition predict insulin sensitivity independently of visceral fat. Diabetes 1997; 46: 1579-1585.

32. Jacob S, Machann J, Rett $\mathrm{K}$, et al. Association of increased intramyocellular lipid content with insulin resistance in lean nondiabetic offspring of type 2 diabetic subjects. Diabetes 1999; 48: 1113-1119.

33. Krssak M, Falk Petersen K, Dresner A, et al. Intramyocellular lipid concentrations are correlated with insulin sensitivity in humans: a 1H NMR spectroscopy study. Diabetologia 1999; 42: 113-116.

34. Pan DA, Lillioja S, Kriketos AD, et al. Skeletal muscle triglyceride levels are inversely related to insulin action. Diabetes 1997; 46: 983-988.

35. Perseghin G, Scifo P, De Cobelli F, et al. Intramyocellular triglyceride content is a determinant of in vivo insulin resistance in humans: a $1 \mathrm{H}-13 \mathrm{C}$ nuclear magnetic resonance spectroscopy assessment in offspring of type 2 diabetic parents. Diabetes 1999; 48: $1600-1606$.

36. Phillips DI, Caddy S, Ilic V, et al. Intramuscular triglyceride and muscle insulin sensitivity: evidence for a relationship in nondiabetic subjects. Metabolism 1996; 45: 947-950.

37. Simoneau JA, Colberg SR, Thaete FL, Kelley DE. Skeletal muscle glycolytic and oxidative enzyme capacities are determinants of insulin sensitivity and muscle composition in obese women. FASEB J 1995; 9: 273-278.

38. Goodpaster BH, Kelley DE, Wing RR, Meier A, Thaete FL. Effects of weight loss on regional fat distribution and insulin sensitivity in obesity. Diabetes 1999; 48: 839-847.

39. Storlien LH, Jenkins AB, Chisholm DJ, Pascoe WS, Khouri S, Kraegen EW. Influence of dietary fat composition on development of insulin resistance in rats. Relationship to muscle triglyceride and omega-3 fatty acids in muscle phospholipid. Diabetes 1991; 40: 280-289.

40. Thamer C, Machann J, Bachmann O, et al. Intramyocellular lipids: anthropometric determinants and relationships with maximal aerobic capacity and insulin sensitivity. $J$ Clin Endocrinol Metab 2003; 88: 1785-1791.

41. Pruchnic R, Katsiaras A, He J, Kelley DE, Winters C, Goodpaster BH. Exercise training increases intramyocellular lipid and oxidative capacity in older adults. Am J Physiol Endocrinol Metab 2004; 287: E857-E862.

42. Dube JJ, Amati F, Stefanovic-Racic M, Toledo FG, Sauers SE, Goodpaster BH. Exercise-induced alterations in intramyocellular lipids and insulin resistance: the athlete's paradox revisited. Am J Physiol Endocrinol Metab 2008; 294: E882-E888.

43. Belfort R, Mandarino L, Kashyap S, et al. Dose-response effect of elevated plasma free fatty acid on insulin signaling. Diabetes 2005; 54: 1640-1648.

44. Dresner A, Laurent D, Marcucci M, et al. Effects of free fatty acids on glucose transport and IRS-1-associated 
phosphatidylinositol 3-kinase activity. $J$ Clin Invest 1999; 103: 253-259.

45. Hoeks J, Hesselink MK, Russell AP, et al. Peroxisome proliferator-activated receptor-gamma coactivator-1 and insulin resistance: acute effect of fatty acids. Diabetologia 2006; 49: $2419-2426$.

46. Kashyap SR, Belfort R, Berria R, et al. Discordant effects of a chronic physiological increase in plasma FFA on insulin signaling in healthy subjects with or without a family history of type 2 diabetes. Am J Physiol Endocrinol Metab 2004; 287: E537-E546.

47. Cusi K, Kashyap S, Gastaldelli A, Bajaj M, Cersosimo E. Effects on insulin secretion and insulin action of a 48-h reduction of plasma free fatty acids with acipimox in nondiabetic subjects genetically predisposed to type 2 diabetes. Am J Physiol Endocrinol Metab 2007; 292: E1775-E1781.

48. Santomauro AT, Boden G, Silva ME, et al. Overnight lowering of free fatty acids with Acipimox improves insulin resistance and glucose tolerance in obese diabetic and nondiabetic subjects. Diabetes 1999; 48: 1836-1841.

49. Kim JK, Gimeno RE, Higashimori T, et al. Inactivation of fatty acid transport protein 1 prevents fat-induced insulin resistance in skeletal muscle. $J$ Clin Invest 2004; 113: 756-763.

50. Itani SI, Ruderman NB, Schmieder F, Boden G. Lipid-induced insulin resistance in human muscle is associated with changes in diacylglycerol, protein kinase C, and IkappaB-alpha. Diabetes 2002; 51: 2005-2011.

51. Yu C, Chen Y, Cline GW, et al. Mechanism by which fatty acids inhibit insulin activation of insulin receptor substrate-1 (IRS1)-associated phosphatidylinositol 3-kinase activity in muscle. J Biol Chem 2002; 277: 50230-50236.

52. Aguirre V, Werner ED, Giraud J, Lee YH, Shoelson SE, White MF. Phosphorylation of Ser307 in insulin receptor substrate-1 blocks interactions with the insulin receptor and inhibits insulin action. $J$ Biol Chem 2002; 277: 1531-1537.

53. Griffin ME, Marcucci MJ, Cline GW, et al. Free fatty acid-induced insulin resistance is associated with activation of protein kinase $\mathrm{C}$ theta and alterations in the insulin signaling cascade. Diabetes 1999; 48: 1270-1274.

54. Kim JK, Fillmore JJ, Sunshine MJ, et al. PKC-theta knockout mice are protected from fat-induced insulin resistance. $J$ Clin Invest 2004; 114: 823-827.
55. Berti L, Mosthaf L, Kroder G, et al. Glucose-induced translocation of protein kinase $\mathrm{C}$ isoforms in rat-1 fibroblasts is paralleled by inhibition of the insulin receptor tyrosine kinase. $J$ Biol Chem 1994; 269: 3381-3386.

56. Chin JE, Dickens M, Tavare JM, Roth RA. Overexpression of protein kinase C isoenzymes alpha, beta I, gamma, and epsilon in cells overexpressing the insulin receptor. Effects on receptor phosphorylation and signaling. J Biol Chem 1993; 268: 6338-6347.

57. Chin JE, Liu F, Roth RA. Activation of protein kinase C alpha inhibits insulin-stimulated tyrosine phosphorylation of insulin receptor substrate-1. Mol Endocrinol 1994; 8: 51-58.

58. De Fea K, Roth RA. Protein kinase C modulation of insulin receptor substrate-1 tyrosine phosphorylation requires serine 612. Biochemistry 1997; 36: 12939-12947.

59. Greene MW, Morrice N, Garofalo RS, Roth RA. Modulation of human insulin receptor substrate-1 tyrosine phosphorylation by protein kinase Cdelta. Biochem J 2004; 378: 105-116.

60. Samuel VT, Liu ZX, Wang A, et al. Inhibition of protein kinase Cepsilon prevents hepatic insulin resistance in nonalcoholic fatty liver disease. J Clin Invest 2007; 117: 739-745.

61. Cortright RN, Azevedo JL, Zhou Q Jr., et al. Protein kinase C modulates insulin action in human skeletal muscle. Am J Physiol Endocrinol Metab 2000; 278: E553-E562.

62. Perdomo G, Commerford SR, Richard AM, et al. Increased betaoxidation in muscle cells enhances insulin-stimulated glucose metabolism and protects against fatty acid-induced insulin resistance despite intramyocellular lipid accumulation. $J$ Biol Chem 2004; 279: 27177-27186.

63. Thyfault JP, Cree MG, Zheng D, et al. Contraction of insulinresistant muscle normalizes insulin action in association with increased mitochondrial activity and fatty acid catabolism. Am J Physiol Cell Physiol 2007; 292: C729-C739.

64. Koves TR, Li P, An J, et al. Peroxisome proliferator-activated receptor-gamma co-activator 1alpha-mediated metabolic remodeling of skeletal myocytes mimics exercise training and reverses lipid-induced mitochondrial inefficiency. $J$ Biol Chem 2005; 280: 33588-33598. 